\title{
Basic biological aspects of Tritrichomonas foetus of relevance to the treatment of bovines suffering of trichomoniasis
}

\author{
Newton Soares da Silva ${ }^{1,3^{*}}$, Susane Moreira Machado ${ }^{1}$, Fernando Costa e Silva Filho ${ }^{2}$, \\ Cristina Pacheco-Soares ${ }^{1,3}$
}

${ }^{1}$ Laboratório de Biologia Celular e Tecidual, Instituto de Pesquisa e Desenvolvimento, Universidade do Vale do Paraíba, São José dos Campos, São Paulo, Brasil; *Corresponding Author: nsoares@univap.br

${ }^{2}$ Instituto de Biofísica Carlos Chagas Filho, Universidade Federal do Rio de Janeiro, CCS - Bloco G, Rio de Janeiro, Brasil;

${ }^{3}$ Laboratório de Dinâmica dos Compartimentos Celulares, Instituto de Pesquisa e Desenvolvimento, Universidade do Vale do Paraíba, São José dos Campos, São Paulo, Brazil.

Received 8 June 2011; revised 14 July 2011; accepted 25 July 2011.

\begin{abstract}
Tritrichomonas foetus is a flagellate protozoan and the etiological agent of bovine genital trichomoniasis [1], which is an infectious venereal disease. This parasite is usually found associated with the mucosal surface of the urogenital tract in females or the male preputial and penile membranes. In females, the clinical manifestations may include abortion, with repetition of estrus at irregular intervals, vaginitis, cervicitis, endometritis, and pyometra. Parasitized males may have a discharge with small nodules in the preputial membrane. After that, the bulls have no clinical symptoms, and are thus an asymptomatic carrier that may spread the infection. Considering that a bull could cover up to twenty females [2], bovine genital trichomoniasis is a serious medical and veterinary problem, with economical repercussion for beef and milk production. As $T$. foetus is an amitochondrial and aerotolerant organism, energy production under low $\mathrm{O}_{2}$ tension in the protozoan is done via hydrogenosome, which, as the name suggests, is the organelle where $\mathrm{H}_{2}$ is generated $[3,4,5]$. The molecular machinery of mitochondrial cell death is, therefore, absent in this parasite and the mechanism that activates of cell death program is not clear. This review seeks to understand the characteristics of the protozoan parasite $T$. foetus in order to propose new therapies for animals suffering from this infectious and contagious agent.
\end{abstract}

Keywords: Reproduction; Protozoan Parasite;
Tritrichomonas foetus

\section{INTRODUCTION}

Tritrichomonas foetus, Reidmüller 1928 emend. Kirby 1947, is a flagellate protozoan that lives in oxygen-poor environments, such as the bovine reproductive tract [6]. This protozoan is found in the urogenital mucosal surface of males and females, causing bovine trichomoniasis, an infectious disease with venereal transmission, which causes infertility and abortion in cattle increasing herd management expenses $[7,8]$. Trichomoniasis is probably the third most common cause of abortion in cattle (after Brucellosis and Leptospirosis) [7]. This disease has worldwide distribution [8], and is endemic especially in regions with poor sanitary control or where the use of natural mating for reproduction is extensive [9].

T. foetus is physically associated with the epithelium lining the urogenital cavities of cattle [10,11]. In bulls, the parasite can be detected in the preputial cavity and urethra, as well as in the urogenital canal [11,12]. In cows, it inhabits the vagina and uterus, in which the parasite can inhibit the attachment of embryo or rupture its membranes after attachment, leading to abortion [10,11,13].

Despite the economic importance attributed to bovine trichomoniasis, there have been few studies about the molecular basis and chemotherapy of disease, thus it has failed to be eradicated, or even rigorously control. Therefore, the disease continues to cause problems for Brazilian and other cattle [9].

\subsection{Morphofunctional Characteristics of $T$. foetus}

\subsubsection{General Aspects}

Tritrichomonas foetus Kirby, 1947 belongs to the 
family Trichomonadidae, order Trichomonadida Kirby, 1947, class Zoomastigophora, subphylum Mastigophora, Sarcomastigophora, phylum Sarcomastigophora, subkingdom Protozoa, and kingdom Protista [14].

Tritrichomonas foetus, Tritrichomonas suis (parasite of the digestive tract and nasal cavity of pigs) and Tritrichomonas mobilensis (parasite of the digestive tract, especially the cecum and colon in monkeys) were found after analyzing gene sequences to probably be strains or variants of the same species $[10,15,16]$.

T. foetus is a monogenic and monoxenic protozoan, which is aerotolerant and actively mobile. It reproduces by binary division and in vitro, axenic culture. The predominant form of trophozoite is approximately 10 to 25 $\mu \mathrm{m}$ long by 3 to $15 \mu \mathrm{m}$ wide. However, both in vitro and in vivo or in situ, the parasite has morphology that varies from pyriform to fusiform or even round. It characteristically has three free anterior flagella and a quarter, anteroposterior projection, which is occasionally associated with the plasma membrane, resulting in a structure known as the undulating membrane. This, in turn, is associated internally to coast. The axostil, an organelle formed by parallel bundles of microtubules and anteroposterior projection, projects itself externally in the form of terminal spine [10]. Axostil and pelta, parts of the cytoskeleton, together with the coast and flagella are jointly involved in motor functions and cell division of the parasite $[10,17]$. The other intracellular structures of $T$. foetus are the parabasal body (Golgi apparatus and parabasal filaments), the oval nucleus (located in the anterior third of the body), and hydrogenosomes (functional replacements of the mitochondria). The cytoplasm also has a wide variety of vacuoles and vesicles related to the encytosis, digestion, and transport processes, as well as rough endoplasmic reticulum, free ribosomes, and glycogen granules [17]. The nutrient uptake in $T$. foetus can occur by diffusion as well as by phagocytosis and pinocytosis, resulting in the formation of cytoplasmic vacuoles of various sizes [17]. In vitro in axenic and acellular culture, $T$. foetus uses glucose as the principal energy precursor. Even in vivo, where the supply of sugar is almost nonexistent in the initial infection sites, the parasite makes use of precursors in the synthesis of polyamines, such as arginine, to produce the energy needed to survive in the host $[18,19]$.

\subsubsection{Particular Point, the Cell Surface}

The first region the parasite contacts the host envinment is on its surface. Therefore, this organelle plays a crucial role in the etiology of bovine trichomoniasis. From a structural viewpoint, it is defined as a cell surce organelle formed by the plasma membrane and exterlly associated carbohydrates. Studies that focus on tricomo- ds-host cell interaction have shown that the cytotoxicity of $T$. foetus can be triggered from physical contact beeen the surfaces of the parasite and host cell, resulting in the secretion of extracellular proteases and glycosidases [20-22]. Such enzymes, in turn, seem not only to induce cytolysis or the disruption of epithelial junctions, but to remodel the surrounding extracellular matrix (ECM) [23]. Thus, mechanochemical monitoring of the extracellular environment by the surface of the parasite would co-opt the host's ability to constitute a niche and thus to survive in various anatomical sites.

From a molecular standpoint, the surface of trichomonads is a mosaic composed of cytopathic and cytotoxic enzymes, lectins, adhesins, receptors, and co-receptors for ECM components, as well as other molecules involved in adhesion and toxicity of host cell trichomonads [22-28].

Adhesins and cysteine proteases on the surface of $T$. foetus are directly involved in parasite interaction with host cells. A $100-\mathrm{kDa}$ protein characterized as adhesin has been observed throughout the cell surface of $T$. foetus, mainly in the region of the flagella [29]. Cysteine proteases, soluble or associated with the surface of $T$. foetus, are have more cytotoxicity than the cytoadhesion. These proteins induce apoptosis in bovine vaginal epithelial cells (BVECs), which suggests that this mechanism of cell death may be involved in the pathogenesis of these protozoa [30].

A surface molecule of $118 \mathrm{kDa}$ enables $T$. foetus to recognize laminin-1, which is component of ECM of the base membrane of epithelia. The immobilized or soluble fibronectin is also recognized by $T$. foetus via surface glycoconjugates rich in mannose [22,27]. Thus in principle, the $T$. foetus host could not only lyse epithelial cells or break its junctional complexes, it may recognize the ECM host and destroy or reshape it in a timely basis thereby winning in other situations.

Lectins on the surface of $T$. foetus are related to the recognition of portions of oligosaccharides of glycoconjugates on the surface of epithelial cells [22]. Moreover, lectins, together with fluorochromes conjugated or complexed with colloidal gold, react with residues of DGlcNAc, N-acetyl-D-galactosamine, sialic acid, D-mannose, D-glucose, L-fucose, and D-galactose on the surface the protozoan $[20,24]$. Together, these data seem to indicate that, at least in vitro, lectins on the surface oligosaccharides of $T$. foetus could be involved in recognition and parasite adhesion to host cells.

\subsection{Pathogenesis of $T$. foetus}

\subsubsection{Female Genital Tract}

After infection, virtually all of the genital tract be- 
comes contaminated within twenty days. Initially, the parasite multiplies intensively in the vagina and is subsequently located mainly in the folds of the uterine cervix. Infection often leads to a moderate vaginitis with purulent discharge, with or without mild endometriosis and transitory infertility, leading to pyometra, salpingitis, and cervicitis [10,13,31,32].

Protozoa are more numerous between 14 and 18 days after infection. The inflammatory response of the uterus occurs between six to eight weeks after infection and is probably responsible for the death of the embryo. The interruption of pregnancy is usually concentrated in the first weeks of pregnancy, but may extend until the fifth month. The uterus in some females do not become invaded, and thus they can have normal pregnancies and births [10,13,31,32].

From the vagina to the cervix, $T$. foetus then invades the uterus and grows in fetal membranes producing placentitis, detachment, and death of the embryo, by direct action of the protozoa or from the effects of the inflamemation [10,31]. The pathogenic mechanisms that cause embryonic or fetal death have not been understood fully yet. The inflammatory process can vary between acute and chronic, characterized by accumulation of neutronphils, macrophages, lymphocytes, and occasionally plasma cells. The inflammatory reaction that develops in the host, causing changes in the uterine environment, and cytotoxicity mediated by lymphokine, has been suggested as possible mechanisms [10].

The deleterious effects that are caused by $T$. foetus directly on the embryo or fetus have been demonstrated by identifying cysteine proteases of the parasite in cervico-vaginal mucus of experimentally infected cows. These soluble proteases are directly associated with the digestion of host secretions (albumin, fibrinogen) and participate in the processes of iron absorption from lactoferrin [33], in cytoadhesion and acquired immunity (immunoglobulins G1 and G2) [17,26,34].

Abortion of the calf usually occurs between the first and third months of pregnancy, may exceptionally happen after the fifth or sixth months of pregnancy. When there is a complete release of the placenta and fetal membranes, female naturally recover. Retained placenta with membranes can result in chronic catarrhal or purulent endometritis and may result in permanent sterility [13,31].

After the embryonic or fetal death occurs, a period of gradual recovery usually restores uterine fertility within two to six months after the initial exposure to the parasite. If the corpus luteum and macerated fetus remain, the female may develop pyometra, which can cause permanent infertility. The corpus luteum is maintained active, probably due to lack of prostaglandin secretions by the endometrium [17].

In females, the infection is self-limiting, lasting an average of 90 - 95 days, but during that period they may continue transmitting the parasite to bulls through breeding activity [13]. Infected cows harbor the parasite for several estrous cycles or after the termination of pregnancy. $T$. foetus is then removed from the uterus, cervix, and vagina, because of a specific infection induced immune response. However, such immunity is not permanent and females are subject to subsequent reinfections in coitus [17].

\subsubsection{Male Genital Tract}

In the bull the parasite is found on the penis, preputial cavity, and in some cases, the urethral opening. Penile mucosa and adjacent areas of the preputial mucosa have a large concentration of protozoa, which are not invasive, situated in the surface mucosa, in secretions and the glandular light [10,12,35,36,37].

Infected bulls serve as carriers of the parasite and in older animals the infection becomes chronic, possibly because of the increase in the number and depth of the villi of the preputial epithelium in these animals [10,38]. Younger males are less likely to become permanent carriers of the infection in relation to older, nevertheless, they are capable of transmitting the parasite to susceptible females [10].

Typically, males exhibit no macroscopic evidence of infection due to the presence of the parasite, but can remain as carriers throughout their lives, unless they are medicated. There are rare cases of balanitis and acrobustite. These problems, if present, are more of conesquence of associated infections than from the action of the parasite. Histopathological examination of the subepithelial area of the penis and foreskin reveals the presence of a moderate infiltration of neutrophils, macrophages, and lymphocytes, which are often accompanied by an increased number of plasma cells $[10,12,36]$.

\subsection{Immunological Aspects}

Studies on the immune response to infection by $T$. foetus in bulls are scarce. The fact that young animals are more resistant to infection is related more to the microscopic structure of the lining of the penis and foreskin than an effective immune response, which is probably absent in these animals $[10,38]$.

Females are able to develop an effective immune response against $T$. foetus. The parasite stimulates a mild inflammatory response associated with the interruption of pregnancy. Inflammation is mediated by an immune mechanism that often eliminate the infection [17]. In carrier cows, this immune mechanism probably fails, maintaining the infection in the herd [32]. 
After the initial infection with $T$. foetus, bovine females respond with the local secretion of immunoglobulins IgG and IgA in cervico-vaginal mucus secreted by the uterus. The elimination of infection is probably mediated by specific immunoglobulins, since the organism is an extracellular parasite. Monoclonal antibodies cause agglutination and complement mediated lysis that prevent the adhesion of parasites to the epithelial cells of the vagina, thereby facilitating phagocytosis of $T$. foetus by monocytes. The association between specific anti- $T$. foetus antibodies and complement potentiates the death of the parasites by polymorphonuclear leukocytes $[10,39,40]$.

\subsection{Treatment}

Females with $T$. foetus are able to eliminate the infection without therapy, after the adoption of sexual abstinence for ninety days and normal uterine involution. Females who manifest post-coital pyometra should receive appropriate care aimed at the corpus luteum regression and elimination of uterine content [8]. Animals with untreated pyometra can become permanently sterile, which would justify their disposal [17].

The treatment of bulls infected with $T$. foetus has been proposed by some researchers as a complementary measure to eradicate the disease in the herd. However, currently there is no effective drug approved for the treatment of males and females infected with $T$. foetus and the results have not always been satisfactory [8].

Two different forms of treatment are recommended for infected males: topical of the preputial and penile membrane and oral. However, treatments are usually lengthy, often requiring many repetitions, and have varying degrees of side effects such as tissue destruction, loss of appetite, and digestive disorders in orally administered products $[8,17]$.

Employment of trichomonicidal agents, preferably in bulls, is justified by the fact that these animals are the disseminators and hosts of the parasite. In females, sexual abstinence for ninety days can eliminate $T$. foetus. Topical, drugs have been tested with several active ingredients in the elimination of $T$. foetus, such as acriflavine associated with tripaflavine and acriflavine [17]. Orally, imidazole derivatives have been tested, such as metronidazole, ipromidazole, and dimetridazole, with varying results $[17,41]$. Treatment is not recommended for a large number of bulls or to be used indiscriminate in a herd, but should be restricting to high value livestock.

Diseases caused by tricomonads can be cured by the use of 5-nitroimidazoles such as metronidazole, effective against various anaerobic and aerotolerant microorganisms [42]. Via glycolysis, the decarboxylation of pyru- vate to hidrogenosomas $T$. foetus is coupled to ATP synthesis and linked to electron transport mediated by ferridoxin. This pathway is responsible for metabolic activation of 5-nitroimidazoles [3,42]. The antimicrobial effect of these drugs depends more on its interaction with DNA, than its metabolic reduction in the microorganism and the consequent generation of free radicals [43].

Although resistance to metronidazole did not show any alarming clinical problem, some data related to the subject should be taken into consideration. The results of [8] and [44] demonstrated that in vitro and in vivo trichomonads develop resistance in a short period of time, at low drug concentrations. This is alarming because of the possibility of trichomonads resistant strains arising due to inappropriate treatment regimen prescribed to animals carrying the parasite, which seems to have occured with $T$. foetus: strain KV1 MR > 100 [14]. Many if not most drugs used to treat patients with the human and bovine trichomoniasis are nitroimidazole derivatives (2, 3, 4, and 5-nitroimidazoles). Although these drugs have different pharmacokinetics, their intracellular mechanisms of action are based on reducing the nitro grouping $[3,45,46]$.

\subsection{Photodynamic Therapy}

Photodynamic therapy (PDT) uses the combination of a dye or chromophore (photosensitizer) and a light source, usually a LASER [47]. Although PDT was originally developed as a cancer therapy, it also has great therapeutic potential for other mucocutaneous manifestation diseases such as psoriasis, fungal infections, and bacterial infections resistant to antibiotic treatments. Photodynamic therapy with derivatives of phthalocyanines is proving effective in inactivating viruses such as herpes simplex $[48,49,50]$.

The concept of PDT originated in 1900 when Oscar Raab [51] demonstrated that free-living protozoa of the genus Paramecium could be killed by prior incubation with sensitizers and subsequent white light illumination. However, the modern PDT originated with the studies by Lipson and Schwartz in 1960. These investigators observed that injection of hematoporphyrin in tissues of cancer patients, induced the appearance of fluorescence in neoplastic lesions, visible during surgical procedures [52].

\subsubsection{Photosensitizers}

Photosensitizers are chromophors that absorb light energy at specific wavelengths and are able to induce reactions in nonabsorbent molecules [52]. A variety of synthetic photosensitizers has been proposed as the second generation, for example, phthalocyanines and chlo- 
rins. Studies using these photosensitizers have been developed in order to eliminate problems associated with the first generation photosensitizers, which have cutaneous photosensitivity and make inefficient use of light at a low penetration wavelength [53].

The phthalocyanines induce sensitivity to radiation in the wavelength range between $600-1.200 \mathrm{~nm}$, which can be conjugated to a variety of metals such as aluminum and zinc, increasing their lifespan and improving photodynamic toxicity. The presence of side groups in these photosensitizers can change its electrostatic charge and solubility, thereby affecting its uptake by eukaryotic cells. The increase in the sulfonation level of phthalocyanine progressively reduces its affinity for lipid bilayers, making it less phototoxic to mammalian cells. The association of the photosensitizer with the lipid bilayer may be more important than the amount of reactive oxygen produced [53,54].

The transport of the phthalocyanine, in vivo, is usually performed by low-density lipoprotein (LDL). LDL is recognized by receptors on the plasma membrane. The greater the number of receptors for LDL, the greater the incorporation of photosensitizing will be and thus of photodynamic therapy. The incorporation of sensitizers is higher in cells with high mitotic rate, such as tumor and endothelial cells. The phthalocyanine-LDL complex binds to receptors on the plasma membrane and then is internalized via endocytosis. In the intracellular environment, LDL-phthalocyanine is usually in addition to the plasma membrane, in lysosomes and mitochondria $[53,55]$.

\subsubsection{Photodestruction Mechanism}

Photodynamic therapy is characterized by celular photooxidation via prior sensitization of the cell with the photosensitizer present in the target tissue. While many of these photosensitizers may be natural constituents of the tissues, as the first step of treatment, they should be introduced into tissues by direct administration. In the second step, the tissue containing the photosensitizer is irradiated with laser, at the wavelength of maximum absorption of the first. The light interacts with the photosensitizer. In this state, the half life of the photosensitizer is a few millionths of a second, long enough for it to quickly energize the dissolved oxygen, resulting in production of reactive oxygen species or ROS, such as ${ }^{1} \mathrm{O}_{2}, \mathrm{H}_{2} \mathrm{O}_{2}, \mathrm{OH}^{-}$, and $\mathrm{O}_{2}-$. Such species are chemically unstable and highly reactive, which generally causes eukaryotic cell death. Various structures and organelles can be targets for PDT, including the plasma membrane, nucleus, mitochondria, Golgi apparatus, lysosomes, and cytoskeletal structures [56,57].

\subsection{Cell Death, Necrosis and Apoptosis.}

Programmed cell death (PCD) is a genetically regulated physiological process in the development and homeostasis of multi and unicellular organisms [58-61]. Once scientists recognized that organisms are composed of cells, they discovered that cell death could be an important part of life. First observed during the metamorphosis of amphibians, cell death was soon discovered in the normal development of many tissues of both invertebrates and vertebrates [62]. Today, cell death is known to be a remarkable and essential event both in normal cells of organisms and in pathophysiological processes, which can cause diseases [63].

The term "programmed cell death" has been used to describe cell death that occurs in predictable places and times during development, emphasizing that deaths are somehow programmed during the development plan of the organism [62]. Subsequently researchers determined that the process of cell death is the main mechanism controlling the number of cells (differentiation, embryogenesis, metamorphosis, and aging). It also acts in the defense mechanism to remove unwanted cells, which may even potentially be dangerous to the body, and prevent several diseases including cardiomyopathy and cancers [62,64-66]. In some cases, there is degradation of an entire cell, other times it occurs on a subcellular scale due to lack of food in which the cell needs to degrade proteins and certain non-essential organelles to recycle these compounds for reuse in the cytosol [66].

The interest in the process of cell death began to grow rapidly by 1990 when there was a change in the description from, "the cell dies and is replaced" to a new point of view that says, "cell death is not an incident of life, but an important and highly controlled element of existence”. Thus, with the change of emphasis, cell death has become recognized as an interesting biological event [67].

In 1972, Kerr and colleagues (apud [65]), performed classical ultrastructural experiments, which provided evidence that the cells undergo at least two distinct types of cell death: the first known as necrosis and a second called apoptosis. This work led to interest in programmed cell death, first because it provided a visible object (profile apoptosis) to be consistently focused on previous experimental studies in relation to the disappearance of dead cells and secondly it provided evidence for the controlled events that justify the operational definition of "programmed".

In the last decade, apoptosis has attracted great scientific interest. Significant progress has been made in understanding the factors that control survival and cell death as well as the intracellular events associated with the "suicide" cell. However, morphological and biochemical evidence suggest that programmed cell death is 
not confined to apoptosis and necrosis. In many biological systems, cellular suicide has shown the involvement of a lysosomal autophagic compartment. Thus cell death associated with autophagy has been observed in the fungus Dictyostelium discoideum during induction of nutritional stress; physiological stages of development, such as metamorphosis in insects,embryogenesis in mammals with regression of webbing and in adults primarily in the intestine, mammary glands, and ovarian follicles [68].

The clinical implications of understanding programmed death are significant. Identified program components of signal transduction in PCD are potential targets for drug development and new therapies that might activate the cell death program, thereby helping to eradicate pathogens by antibiotics.

Mariante [69] observed that hydrogen peroxide $\left(\mathrm{H}_{2} \mathrm{O}_{2}\right)$ induced activation of caspases and a mechanism of programmed cell death in $T$. foetus. The authors report that: (1) $\mathrm{H}_{2} \mathrm{O}_{2}$ led to loss of motility and induced cell death, (2) dead protozoa exhibited some characteristics similar to those found during cell death of other organisms, (3) a "caspase-like" protein appears to be activated during this process of cell death. They proposed that although $T$. foetus did not show any mitochondria or known cell death pathway, it is likely to have some mechanism of cell death. T. foetus exhibited morphological and physiological changes in response to treatment with $\mathrm{H}_{2} \mathrm{O}_{2}$. Together, these results suggest that a cell death pathway, involving at least one member of the family of caspases, can exist in amitocondrials bodies such as trichomonads. The hydrogenosome has an important role in the oxidative burst in trichomonads and is a candidate to participate in this event [69].

In amitochondrial organisms, such as trichomonads, it has been assumed that the machinery of PCD is absent, but studies by [70] led to the proposal that the existence of both caspase-dependent and caspase-independent mechanisms of cell death may be present in trichomonads.

Preliminary results of PDT in T. foetus [71] the authors observed ultrastructural changes, such as projecttions of the plasma membrane, nuclear fragmentation with masses of heterochromatin in the periphery, proliferation of endoplasmic reticulum, intense vacuolization of cytoplasm, and complex and fragmented axostilar pelta-internalization of flagella. These results were also observed in [69] after treatment with $\mathrm{H}_{2} \mathrm{O}_{2}$, suggesting that oxidative stress induces a mechanism of cell death in this parasite.

\section{CONCLUSIONS}

In animals, the PCD is associated with the elimination of super cells expressed in the development and eradication of others, defective [72]. Teratogenic transformations, microbial infections, lethal factors such as heat, mutagens and oxidants agents, and toxins induce the activation of PCD. Recent studies have shown the existence of PCD in unicellular eukaryotes of different phylogenetic origins, indicating that the conservation of the molecular mechanism is relevant to the functional role of this process in the biology of protozoa [69]. The possible reasons that the apoptosis pathways in protozoa are comparable to those of yeast and bacteria may be to (a) protect populations of healthy cells, (b) obtain nutrients from neighboring cells committing altruistic suicide, and (c) decrease perpetuation of mutations.

Here, we briefly review some $T$. foetus properties which are relevant to the development of new treatments directed towards bovine cattle suffering of trichomoniasis. Several drugs have been used to investigate the cytotoxic effect on $T$. foetus, such as colchicine, vinblastine, cytochalasin B [27], taxol, nocodazole, griseofulvin, lactacyst, and hydrogen peroxide [73]. Da Silva et al. [71] analyzed the cytotoxic effect produced by PDT with aluminum phthalocyanine tetrasulfonated (AlPcS4) photosensitizer on $T$. foetus culture. They demonstrated that PDT killed an amitochondrial organism such as $T$. foetus. In this parasite, PDT induces a type of cell death other than necrosis. Apoptosis or autophagic cell death after PDT in $T$. foetus may benefit bovines by limiting the inflammatory response, which is detrimental and could even be lethal to these animals.

We believe that the results obtained from the study of new therapies such as PDT explained in this article will bring benefits to the treatment of cattle suffering from trichomoniasis. This treatment would be without side effects, which are characteristic of antimicrobial therapy with nitroimidazoles.

\section{ACKNOWLEDGMENTS}

This work has been supported by FAPESP (2008/06654-4), CNPq (309699/2009-6) and CNPq-INCT/INPeTAm (573695/2008-3).

\section{REFERENCES}

[1] Pellegrin, A.O. and Leite, R.C. (2003) Atualização sobreTricomonose genital bovina - Corumbá: Embrapa Pantanal.

[2] Guida, H.G., Ramos, A.A., Coelho, N.M., Ramos, J.A. and Mendonza, T. R. (1972) Incidência de Trichomonas foetus em reprodutores bovinos da região centro-sul do Brasil. Pesq. Agrop. Brazil Veterinary Services, 7, 23-25.

[3] Kulda, J. (1999) Trichomonadslhydrogenosomes and drug resistance. International. Journal for Parasitology, 29, 199-212. doi:10.1016/S0020-7519(98)00155-6

[4] Lindmark, D.G. and Muller, M. (1973) Hydrogenosome a cytoplasmic organelle of the anaerobic flagellate Tri- 
trichomonas foetus and its role in pyruvate metabolism. Journal of. Biological Chemistry, 248, 7724-7728.

[5] Muller, M. (1993) The hydrogenosome. Journal of. General Microbiology, 139, 2879-2889.

[6] Cavalier-Smith, T. (1993) Kingdon protozoa and its 18 phyla. Microbiology Reviews, 57, 953-994.

[7] Bondurant, R.H. (1997) Pathogenesis, diagnosis, and management of Trichomoniasis in cattle. Veterinary Clinics of North America: Food Animal Practice, 13, 345-361.

[8] Gomes, M.J.P. (2008) Tritrichomonas foetus, Faculdade de Veterinária UFRGS, Microbiologia Clínica, 2008-1. http://www.ufrgs.br/labacvet/pdf/Tricho_2008-1.pdf

[9] Pellegrin, A.O. (1999) A campilobacteriose e tricomonose são doenças emergentes? Revista Brasileira Animal Reproduction, 23, 523-531.

[10] Rae, D.O. and Crews, J.E. (2006) Tritrichomonas foetus Veterinary Clinics of Food Animal, 22, 595-611.

[11] Yule, A., Skirrow, S.Z. and Bonduran, R.H. (1989) Bovine trichomoniasis. Parasitology Today, 5, 373-377. doi:10.1016/0169-4758(89)90298-6

[12] Parsonson, I.M., Clark, B.L. and Dufty, J. (1974) The pathogenesis of Tritrichomonas foetus infection in the bull. Australian Veterinary Journal, 50, 421-423. doi:10.1111/j.1751-0813.1974.tb06861.x

[13] Parsonson, I.M., Clark, B.L. and Dufty, J.H. (1976) Early pathogenesis and pathology of Tritrichomonas foetus infection in virgin heifers. Journal of Comparative Pathology, 86, 59-66. doi:10.1016/0021-9975(76)90028-1

[14] Honigberg, B.M. (1963) Evolutionary and systematic relationships in the flagellate order Trichomonadida Kirby. Journal of Protozoology, 10, 10-63.

[15] Kleina, P., Bettim-Bandinelli, J., Bonatto, S.L., Benchimol, M. and Bogo, M. (2004) Molecular phylogeny of Trichomonadidae family inferred from ITS-1, 5.8S rRNA and ITS-2 sequences. International Journal of Parasitology, 34, 963-970. doi:10.1016/j.ijpara.2004.04.004

[16] Tachezy, J., Tachezy, R., Hampl, V., Sedinova, M., Vanacova, S., Vrlik, M., Van Ranst, M., Flegr, J. and Kulda, A.J. (2002) Cattle pathogen Tritrichomonas foetus (Riedmuller, 1928) and pig commensal Tritrichomonas suis (Gruby and Delafond, 1843) belong to the same species. Journal of Eukaryotic Microbiology, 49, 154-163. doi:10.1111/j.1550-7408.2002.tb00360.x

[17] Guimarães, M.A. (2008) Curso PFIZER, Módulo Tricomonose Bovina.

http://www.camposecarrer.com.br/reproducao/Tricomono sebovina.doc

[18] Reis, I.A., Martinez, M.P., Yarlett, N., Johnson, P.J., SilvaFilho, F.C. and Vannier-Santos, M.A. (1999) Inhibition of Polyamine Synthesis Arrests Trichomonad Growth and Induces Destruction of Hydrogenosomes. Antimicrobial Agents and Chemotherapy, 43, 1919-1923.

[19] Yarlett, N. (1988) Polyamine biosynthesis and inhibition in Trichomonas vaginalis. Parasitology Today, 4, 357-360. doi:10.1016/0169-4758(88)90007-5

[20] Bonilha, V.L., Ciavaglia, M.C., De Souza, W. and SilvaFilho, F.C. (1995) The involvement of terminal carbohydrates of the mammalian cell surface in the cytoadhesion of trichomonads. Parasitology Research, 81, 121-126. doi:10.1007/BF00931616

[21] De Carli, G.A., Tasca, T. and Pires Borges, F. (2004)
Tritrichomonas foetus: A scanning electron microscopy study of erythrocyte adhesion associated with hemolytic activity. Veterinary Research, 35, 123-130. doi:10.1051/vetres:2003042

[22] López, L.B., Braga, M.B., López, J.O., Arroyo, R. and Costa e Silva Filho, F. (2000) Strategies by which some pathogenic trichomonads integrate diverse signals in the decision-making process. Academia Brasileira de Ciências, 72, 173-186.

[23] Petrópolis Petropolis, D.B., Fernandes Rodrigues, J.C., Da Rocha-Azevedo, B. and Silva-Filho, F.C. (2008) The binding of Tritrichomonas foetus to immobilized laminin-1 and its role in the cytotoxicity exerted by the parasite. Microbiology, 154, 2283-2290. doi:10.1099/mic.0.2007/015941-0

[24] Benchimol, M. and Bernardino, M.V. (2002) Ultrastructural localization of glycoconjugates in Tritrichomonas foetus. Parasitology Research, 88, 134-143. doi:10.1007/s004360100466

[25] Da Silva, N.S., Dias Filho, B.P. and De Souza, W. (1999) Identification and localization of an adhesin on the surface of Tritrichomonas foetus. Parasitology Research, 85, 984-992. doi:10.1007/s004360050670

[26] Silva-Filho, F.C. and De Souza, W. (1988) The interacttion of Trichomonas vaginalis and Tritrichomonas foetus with epithelial cells in vitro. Cell Structure and Function, 13, 301-310. doi:10.1247/csf.13.301

[27] Silva-Filho, F.C. and De Souza, W. (1986) Effect of colchicine, vimblastine and cytochalasin B on cell surface anionic site of Tritrichomonas foetus. Journal of Protozoology, 33, 6-10.

[28] Silva-Filho, F.C., De Souza, W. and Lopes, J.D. (1988) Presence of laminin-binding proteins in trichomonads and their role in adhesion. Proceedings of the National Academy of the United States of America, 85, 8042-8046. doi:10.1073/pnas.85.21.8042

[29] Da Silva, N.S., Dias Filho, B.P. and De Souza, W. (1996) Structural changes at the site of Tritrichomonas foetus-erythrocyte interaction. Cell Structure and Function, 21, 245-250. doi:10.1247/csf.21.245

[30] Singh, B.N., Lucas, J.J., Hayes, G.R., Kumar, I., Beach, D.H., Frajblat, M., Gilbert, R.O., Sommer, U. and Costello, C.E. (2004) Tritrichomonas foetus induces apoptotic cell death in bovine vaginal epithelial cells. Infection and Immunity, 72, 4151-4158. doi:10.1128/IAI.72.7.4151-4158.2004

[31] Bondurant, R.H. (1985) Diagnosis, treatment and control of bovine trichomoniasis. The Compedium on Continuing Education, 7, S179-188.

[32] Clark, B.L., Dufty, J.H. and Parsonson, I.M. (1983) The effect of Tritrichomonas foetus on calving rates in beef cattle. Australian Veterinary Journal, 60, 71-74. doi:10.1111/j.1751-0813.1983.tb05873.x

[33] Grab, D.J., Lonsdale-Eccles, J.D., Oli, M.W. and Corbeil, L.B. (2001) Lactoferrin-binding proteins of Tritrichomonas foetus. Journal of Parasitology, 87, 1064-1070.

[34] Melo Braga, M.B. (2000) A expressão de cisteíno proteinases em Tritrichomonas foetus é regulada por ferro. Rio de Janeiro, Tese (Mestrado), Universidade Federal do Rio de Janeiro, Instituto de Biofísica Carlos Chagas Filho.

[35] Anderson, M.L., Barr, B.C. and Conrad, P.A. (1994) 
Protozoal causes of reproductive failure in domestic ruminants. Veterinary Clinics of North America: Food Animal Practice, 10, 439-461.

[36] Hammond, D.M. and Bartlett, D.E. (1943) The distribution of Trichomonas foetus in the prepucial cavity of infected bulls. American Journal of Veterinary Research, 4, 143-149.

[37] Roberts, S.J. (1986) Infections disease caused by infertility in cows. In: Roberts, S.J., Ed., Veterinary obstetrics and genital diseases, 3rd Edition, Ann Arbor, MI: Edward Brothers, Inc., 447-455.

[38] Peter, D. (1997) Bovine venereal diseases. In: Younguist, R.B., Ed., Current therapy in large animal theriogenology. Phyladelphia: WB Saunders Co., p.355-63.

[39] Aydintug, M.K., Leid, R.W. and Widders, P.R. (1990) Antibody enhances killing of Tritrichomonas foetus by the alternative bovine complement pathway. Infection and Immunity, 58, 944-948.

[40] Aydintug, M.K., Widders, P.R. and Leid, R.W. (1993) Bovine polymorphonuclear leukocyte killing of Tritrichomonas foetus. Infection and Immunity, 61, 2995-3002.

[41] Kirkwood, M.L., Clemens, D.L. and Johnson, P.J. (2001) Loss of Multiple Hydrogenosomal Proteins Associated with Organelle Metabolism and High-Level Drug Resistance in Trichomonads. Experimental Parasitology, 97, 102-110. doi:10.1006/expr.2001.4587

[42] Land, K.M., Clemens, D.L. and Johnson, P.J. (2001) Loss of Multiple Hydrogenosomal Proteins Associated with Organelle Metabolism and High-Level Drug Resistance in Trichomonads. Experimental Parasitology, 97, 102-110. doi:10.1006/expr.2001.4587

[43] Edwards, D.I. (1993) Nitroimidazole drugs-action and resistance mechanism. 1. Mechanism of action. Journal of Antimicrobial Chemotherapy, 31, 2-20. doi:10.1093/jac/31.1.9

[44] Meingassner, J.G. and Mieth, H. (1976) Cross-resistance of trichomonads to 5-nitroimidazole derivatives. Experientia, 32, 183-184. doi:10.1007/BF01937754

[45] Edwards, D.I. (1980) Mechanisms of selective toxicity of metronidazole and other nitroimidazole drugs. British Journal of Venereal Diseases, 56, 285-290.

[46] Moreno, S.N.J. and Docampo, R. (1985) Mechanism of Toxicity of Nitro Compounds Used in the Chemotherapy of Trichomoniasis. Environmental Health Perspectives, 64, 199-208. doi:10.1289/ehp.8564199

[47] Ferreira, S.R.M., Tedesco, A.C., Sousa, G., Zângaro, R.A., Silva, N.S., Pacheco, M.T.T. and Pacheco-Soares, C. (2004) Analysis of mitochondria, endoplasmic reticulum and actin filaments after PDT with $\mathrm{AlPcS}_{4}$. Lasers in Medical Science, 18, 207-212. doi:10.1007/s10103-003-0282-6

[48] Calzavara-Pinton, P.G., Venturini, M., Capezzera, R., Sala, R. and Zane, C. (2004) Photodynamic therapy of interdigital mycoses of the feet with topical application of 5-aminolevulinic acid. Photodermatology, Photoimmunology and Photomedicine, 20, 144-147. doi:10.1111/j.1600-0781.2004.00095.x

[49] Hamblin, M.R. and Hasan, T. (2004) Photodynamic therapy: A new antimicrobial approach to infectious disease? Photochemdicine Photobiology, 3, 436-450. doi:10.1039/b311900a
[50] Machado, A.E.H. (2000) Terapia fotodinâmica: Princípios, potencial de aplicação e perspectivas. Quimica Nova, 23, 237-243. doi:10.1590/S0100-40422000000200015

[51] Raab, O. (1990) Uber die wirkung fluoreszierenden stoffen. Infusuria Z. Biology, 39, 524-546.

[52] Sibata, C.H., Colussi, V.C., Oleinick, N.L. and Kinsella, T.J. (2000) Photodynamic therapy: A new concept in medical treatment. Brazil Journal of Medical and Biological Research, 33, 869-880. doi:10.1590/S0100-879X2000000800002

[53] Fisher, A.M.R., Murphree, A.L. and Gomer, C.J. (1995) Clinical and preclinical photodynamic therapy. Lasers in Surgery and Medicine, 17, 2-31. doi:10.1002/lsm.1900170103

[54] Rokitskaya, T. I., Block, M., Antonenko, Y. N., Kotova, E. A. and Polt, P. (2000) Photosensitizer binding to lipid bilayers as a precondition for the photoinactivation of membrane channels. Biophysical Journal, 78, 2572-2580. doi:10.1016/S0006-3495(00)76801-9

[55] Martins, J., Almeida, L. and Laranjinha, J. (2004) Simultaneous production of superoxide radical and singlet oxygen by sulphonated chloroaluminum phthalocyanine incorporated in human low density lipoproteins. Implications for photodynamic therapy. Photochemistry and Photobiology, 80, 267-273. doi:10.1562/2004-03-26-RA-124.1

[56] Pazos, M.C., Pacheco-Soares, C., Da Silva, N.S., Damatta, R.A. and Pacheco, M.T.T. (2003) Ultrastructural effects of two phthalocyanines in CHO-K1 and HeLa cells after laser irradiation. Biology of the Cell, 27, 301-309.

[57] Schieke, S.M., Von Montfort, C., Buchczyk, D.P., Timmer, A., Grether-Beck, S., Krutmann, J., Holbrook, N.J. and Klotz, L.O. (2004) Singlet oxygen-induced attenuation of growth factor signaling: Possible role of ceramides. Free Radicals Research, 38, 729-737. doi:10.1080/10715760410001712764

[58] Jacobson, M.D., Weil, M. and Raff, M.C. (1997) Programmed cell death in animal development. Cell, 88, 347-354. doi:10.1016/S0092-8674(00)81873-5

[59] Meier, P., Finch, A. and Evan, G. (2000) Apoptosis in development. Nature, 407, 796-801. doi:10.1038/35037734

[60] Steller, H. (1995) Mechanisms and genes of cellular suicide. Science, 267, 1445-1449. doi:10.1126/science.7878463

[61] Vaux, D.L. and Korsmeyer, J. (1999) Cell death in development. Cell, 96, 245-254. doi:10.1016/S0092-8674(00)80564-4

[62] Mignotte, B. and Vayssiere, J.L. (1998) Mitochondria and apoptosis. European Journal of Biochemistry, 15, 1-15. doi:10.1046/j.1432-1327.1998.2520001.x

[63] Lemasters, J.J. (2005) Dying a thousand deaths: Redundant pathways from different organelles to apoptosis and necrosis. Gastroenterology, 129, 351-360. doi:10.1053/j.gastro.2005.06.006

[64] Candal, E., Anadón, R., Degrip, W.J. and RodríguezMoldes, I. (2005) Patterns of cell proliferation and cell death in the developing retina and optic tectum of the brown trout. Developmental Brain Research, 154, 101-119. doi:10.1016/j.devbrainres.2004.10.008 
[65] Guimarães, C.A. and Linden, R. (2000) Programmed cell deaths. European Journal of Biochemistry, 271, 1638-1650.

[66] Klionsky, D.J. and Emr, S.D. (2000) Autophagy as a regulated pathway of cellular degradation. Science, 290, 1717-1721. doi:10.1126/science.290.5497.1717

[67] Lockshin, R.A. and Zakeri, Z. (2001) Programmed cell death and apoptosis: Origins of the theory. Nature Reviews Molecular Cell Biology, 2, 545-550. doi:10.1038/35080097

[68] Bursch, W., Hochegger, K., Torok, L., Marian, B., Ellinger, A. and Hermann, R.S. (2000) Autophagic and apoptotic types of programmed cell death exhibit different fates of cytoskeletal filaments. Journal of Cell Science, 113, 1189-1198. doi:10.1007/s00418-003-0548-x

[69] Mariante, R.M., Guimarães, C.A., Linden, R. and Benchimol, M. (2003) Hydrogen peroxide induces caspase activation and programmed cell death in the amitochondrial Tritrichomonas foetus. Histochemistry and Cell
Biology, 120, 129-141.

[70] Mariante, R.M., Vancini, R.G. and Benchimol, M. (2006) Cell death in trichomonads: New insights. Histochemistry and Cell Biology, 125, 545-556. doi:10.1007/s00418-005-0098-5

[71] Da Silva, N.S., Ribeiro, C.M., Machado, A.H.A. and Pacheco-Soares, C. (2007) Ultrastructural changes in Tritrichomonas foetus after treatments with AlPcS4 and photodynamic therapy. Veternary Parasitology, 146, 175-181. doi:10.1016/j.vetpar.2007.02.006

[72] Metzstein, M.M., Stanfield, G.M. and Horvitz, H.R. (1998) Genetics of programmed cell death in C. elegans: Past, present and future. Trends in Genetics, 14, 410-416. doi:10.1016/S0168-9525(98)01573-X

[73] Vancini, R.G. and Benchimol, M. (2005) Appearance of virus-like particles in Tritrichomonas foetus after drug treatment. Tissue and Cell, 37, 317-323. doi:10.1016/j.tice.2005.03.009 